\title{
CAD/CAM applications: status and impact in Nigerian industrial sector
}

\author{
O.E. Simolowo, F. C. Okonkwo and O. O. Kehinde \\ Department of Mechanical Engineering, University of Ibadan, Nigeria. \\ esimmar@yahoo.com
}

\begin{abstract}
This research assessed, among others, the current status and the impact of Computer-Aided Design (CAD) and Computer-Aided Manufacturing (CAM) applications in the Nigerian industrial and technological sector. Two prominent cities Lagos and Ibadan were selected as centers of case studies to establish the level of the applications. Data was collected from industries within the 2 cities in the areas of manufacturing, design, production, construction and consultancy service units during a year long study. From the survey, $56 \%$ of companies visited in Lagos metropolis apply Computer-Aided Engineering (CAE) activities in their operations. Also 60\% of the companies considered in Ibadan metropolis apply CAE, of which $75 \%$ are into CAD, $12.5 \%$ are applying CAM whereas $12.5 \%$ are utilizing Computer Numerically Controlled (CNC) machines. Conclusively, the commonest CAD techniques employed by the industries surveyed are Auto CAD and Archi CAD representing 55.6\% and 33.3\% of the total packages being used in the visited companies respectively.
\end{abstract}

Keywords: CAD/CAM-applications, Improvements, Nigerian-industries status.

\section{Introduction}

The application of Computer-Aided Design (CAD)/ Computer-Aided Manufacturing (CAM) systems and their associated advantages in various aspects of engineering activities has received considerable attention over the years (Paul Arthur, 1985; William, 1988; Larry, 1990; Kehinde, 2002). The manufacturing sector which is the largest contributor to the Gross Domestic Product (GDP) of the developed nations of the world such as United States of America, Japan, Germany, and Singapore and the like nations is yet to find its rhythm in developing countries such as Nigeria. Surveys have also shown that there is a rapid increase in the use of Computer-Aided Engineering (CAE) systems in developed countries in the recent years due to the benefits derived from such methods. Shown in Table 1 below are the representative levels of application of CAD/CAM system in some developed nations (Daniel, 1989). The problems of the manufacturing sector have often been attributed to inadequate infrastructure and absence of a sound technological base in these developing nations. Against this background, it is now important to look at the involvement of CAE in Nigeria's technological and Industrial sector.

Though this work considers the prospects of CAE in industries, it does not make researchers/engineers in this area of study an end user or developer of CAD/CAM technology without taking courses or training on CAE into consideration: but brings out the capabilities of CAD/CAM which the researcher/engineer can utilize to increase creativity and productivity. Various CAE tasks have been considered and how the use of computer

Research article

CIndian Society for Education and Environment (iSee) graphics enables these tasks to be linked directly with the design activity, allowing a full integration of design, analysis and manufacture in a single CAE system. Similarly, government's role in implementing a full integration of CAE in Nigeria has been treated and suggestions of how CAD/CAM and other Computerbased applications should feature (or be taught) in the curricula of Nigeria's tertiary institutions are also given. Therefore, this study assesses the present status of CAE technologies in Nigeria and outlines the benefits of implementing a fully integrated CAE system in Nigerian manufacturing sector.

\section{Methodology of study}

Administration of questionnaire: Data collection using questionnaire was the main tool towards the conduction of this research. Questions which were brief but concise were drafted and given to engineers, technologies, technicians and administrative managers in 28 applicable companies to assess their level of CAE education and involvement in company's practices. Numerous CAE packages were listed and problems encountered using the listed CAE packages by the respondent were also gathered.

Interaction/interview: Interactive sections were held with the categories of labour force mentioned earlier as a
Table 1. CAD/CAM applications in some developed nations

\begin{tabular}{|c|c|}
\multicolumn{2}{c|}{ in recent years } \\
\hline $\begin{array}{c}\text { Country/ } \\
\text { continent }\end{array}$ & $\begin{array}{c}\text { CAD/CAM } \\
\text { applications in } \\
\text { industrial sector }\end{array}$ \\
\hline U.S.A. & $95 \%$ \\
\hline Japan & $90 \%$ \\
\hline $\begin{array}{c}\text { Western } \\
\text { Europe }\end{array}$ & $50 \%$ \\
\hline \multicolumn{2}{|c|}{ "Nigerian industry" } \\
http://www.indjst.org
\end{tabular}
group and individually. This allowed free expressions of problems and expectations of the industries from the government and education institutions. Visitation: In addition to the distribution of questionnaires, several visits were made to the industries in respect of the issues highlighted in the questionnaire Indian J.Sci.Technol. 
as regards problems being encountered in specified $\mathrm{CAE}$ packages.

Proffering solutions: Solutions to the problems faced by companies applying CAE activities were presented and various ways of improving CAE applications in these industries were recommended. Industries that were not applying CAD/CAM methods were informed of the huge benefits of CAE and advised to make a start.

Viability assessment methods

The engineering economy studies on capital investments that were considered in this study are presented in this section. These cost analysis methods (Ajayi, 1998) determine whether a project is economically viable or a proposed capital investment such as CAD/CAM applications is recoverable in view of risks involved.

Return on investment

Whether a proposed capital investment and its associated expenditures can be recovered by revenue (or savings) over time in addition to a return on the capital that is sufficiently attractive in view of the risks involved and the alternative uses is what return on investment (ROI) considers.

In calculating the $\mathrm{ROI}$ of a numerical control machine, using cost-saving analysis, the relationship given in (1) is used.

Avenafe Daving

Invertment

Where savings include: savings from direct labour costs and profit from increased productivity. Investment include: Acquisition cost; Maintenance cost; Setup/installation cost, such as those involved in the acquisition and installation of CAD/CAM equipments. From (1) productivity comparison between NC used CAD/CAM and conventional machines is made.

\section{The present worth method}

The present worth (PW) method also determines whether a project such as CAE application in industries is a desirable investment. It is based on the concept of equivalent worth of all cash flows relative to some base or beginning point in time called the present. This is presented in (2).

$P W(1 \%)=F_{0}(1+1)^{0}+P_{1}(1+1)^{1}+F_{2}(1+1)^{2}+F_{K}(i+1)^{K}+\cdots+P_{N}(1+1)^{\mathbb{N}}=\sum_{\mathbb{N}}^{K=0} F_{K}(1+1)^{K} \ldots \ldots(2)$

Where $\mathrm{i}=$ effective interest rate or MARR (Minimum Acceptable Rate of Return), per compounding period $k=$ index for each compounding period $(0 \leq k \leq N)$

$F_{k}=$ future cash flow of the end of period $\mathrm{K}$
$\mathrm{N}=$ number of compounding periods in the planning period.

As long as the PW (that is, present equivalent of cash inflows minus cash outflows) is greater than or equal to zero, the project is economically justified; otherwise, it is not acceptable. A present worth analysis of future profitability in embarking on new CAD/CAM techniques using a cash flow diagram (Fig. 1) expounds the study further.

\section{Fig. 1. Cash flow diagram}

Positive Cash (Revenue)
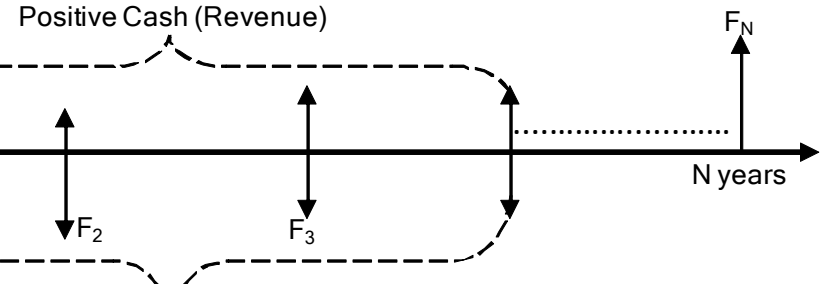

Negative Cash (Expenditure)

Results and discussion

As shown in Fig. 2, 100\% retrieval of questionnaires
Table 2. Impact of CAD/CAM applications in surveyed companies

\begin{tabular}{l|l|} 
aspect or activity & on industrial activity \\
\hline Engineering & Reduction \\
design (cost) & $30 \%-60 \%$ \\
\hline Overall lead-time & $\begin{array}{l}\text { Reduction } \\
30 \%-60 \%\end{array}$ \\
\hline Product quality & Improved \\
\hline $\begin{array}{l}\text { Capability of } \\
\text { engineers }\end{array}$ & Improved \\
\hline $\begin{array}{l}\text { Production } \\
\text { operations }\end{array}$ & $\begin{array}{l}\text { Increased } \\
40 \%-70 \%\end{array}$ \\
\hline $\begin{array}{l}\text { Productivity of } \\
\text { capital equipment }\end{array}$ & $\begin{array}{l}\text { Increased by over } \\
100 \%\end{array}$ \\
\hline $\begin{array}{l}\text { Work done in a } \\
\text { single process }\end{array}$ & $\begin{array}{l}\text { Reduction } \\
30 \%-60 \%\end{array}$ \\
\hline $\begin{array}{l}\text { Cost on needed } \\
\text { personnel }\end{array}$ & $\begin{array}{l}\text { Reduction } \\
5 \%-20 \%\end{array}$ \\
\hline
\end{tabular}
and inquiries sent out were realized for the consultancy, production and research sectors. Individual contacts were also made for proper harnessing of information. General computer applications in the industries were assessed, such as engineering design analysis, monitoring and controlling operations, Computer integrated manufacturing (CIM), Computer numerical control (CNC) and computational fluid dynamics (CFD). Each application was evaluated to establish the extent of its utilisation. A number of relevant CAD/CAM packages or software in use in the industries were recorded as shown in Fig. 3, from which the software commonly used by the majority of the industries was obtained. The impact of computer aided engineering was found out for some companies as presented in Table 2. A measure of the impact is the rate at which it increases or decreases productivity, saves time and controls quality of products. Information on problems encountered on using specified CAE packages and methods of staff development were also analysed and results presented in Fig. 4. The distribution analysis of percentage of staff with computer experience was also carried out as presented in Fig. 5. The final results obtained were then validated using cost analysis methods discussed earlier. This was done to show the reliability of 
embarking on CAD/CAM investments and hence stressing the importance of survey work.

Furthermore, analysis of data collected during the study (Kehinde, 2002; Okonkwo, 2002) showed that there is a skills and training problem in the Nigerian industries. This is evident from the level of industrial staff with CAE experience as shown in Fig. $5 \& 6$. Fig. 3 shows that AutoCAD is the software commonly used by majority of the industries implementing computer aided engineering (CAE), followed by Autodesk Inventor, Archi-CAD and 3D-studio in that order. Also Fig. 4 shows that only few industries are connected to the World Wide Web where

\section{Fig. 2. Sampling frame work (questionnaire)}

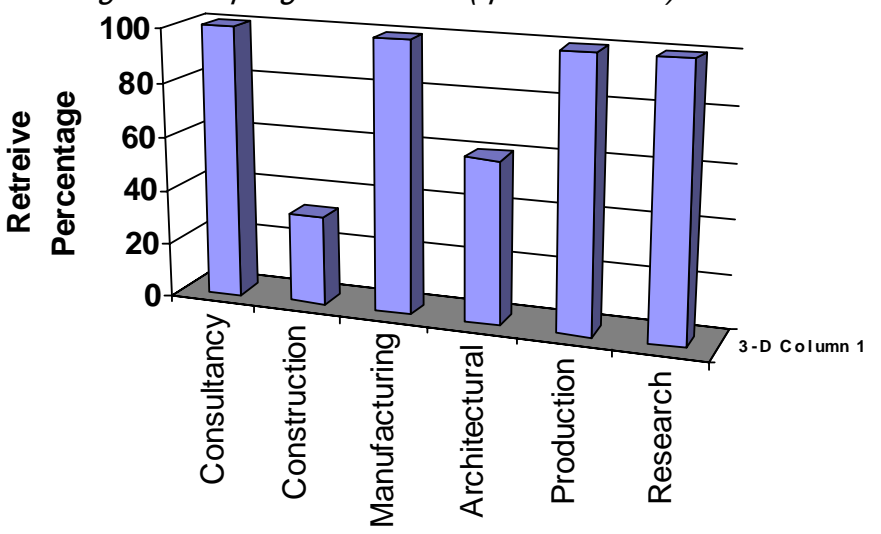

Type of Industry

technical support and software updates can be obtained. A summary of result findings for various companies visited during the survey. The investigation reveals that none of the industries is running a fully integrated computer aided engineering system of operation. This is because these industries have fixed products and operations. Any modification to production is done with the use of equipment and processes that are already in existing in the plant. Conventionally, $70 \%$ of the manufacturing process is done manually while $30 \%$ involves the use of computers. The main area of computer application is in the design of new products or where modification is needed. Further assessments revealed that testing of a proposed product is done in some companies using auto desk Inventor by simulating its performance under various conditions without actually manufacturing the product. Fig. 7 finally shows the broad divisions of computer-

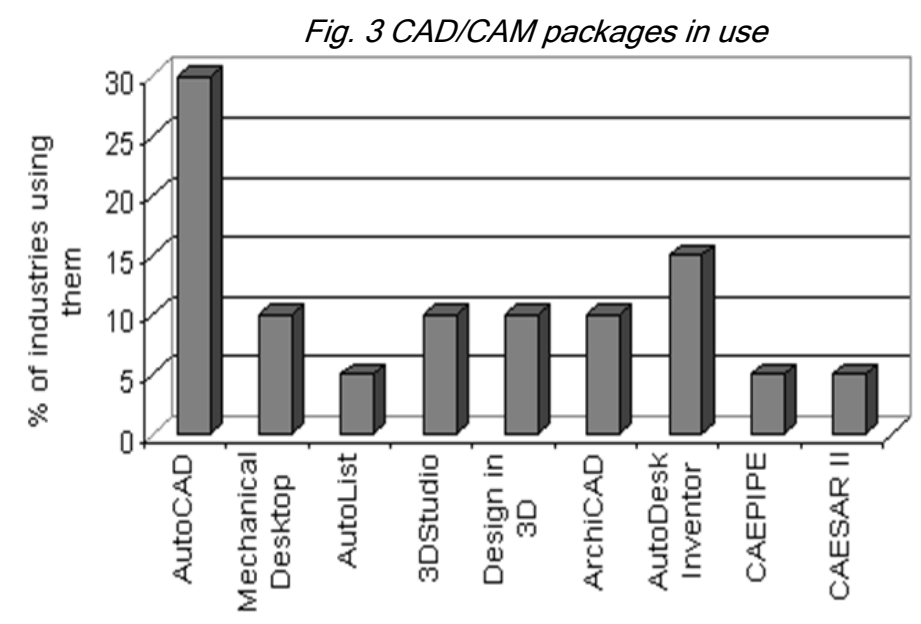

CAE Packages aided engineering (CAE) applied in the companies surveyed with CAD the most commonly utilised while computer-aided process planning (CAPP) and CNC are the least applied.

Table 3. Summary of result findings

\begin{tabular}{|c|c|c|}
\hline $\begin{array}{l}\text { Type of } \\
\text { industry }\end{array}$ & $\begin{array}{l}\text { Applicable } \\
\text { companies }\end{array}$ & $\begin{array}{c}\text { Detailed applications of } \\
\text { CAD/CAM }\end{array}$ \\
\hline \multirow{5}{*}{$\begin{array}{l}\text { Material } \\
\text { processing } \\
\text { industries }\end{array}$} & $\begin{array}{l}\text { Glass } \\
\text { Manufacturing }\end{array}$ & \multirow{5}{*}{$\begin{array}{c}50 \% \text { use Auto CAD for } \\
\text { generating drawing } \\
20 \% \text { use CNC machines for } \\
\text { packaging materials } \\
60 \% \text { use CAM in monitoring } \\
\text { and controlling operations. }\end{array}$} \\
\hline & Polymers & \\
\hline & Textiles & \\
\hline & $\begin{array}{l}\text { Consumer } \\
\text { Products }\end{array}$ & \\
\hline & $\begin{array}{l}\text { Food } \\
\text { Industries }\end{array}$ & \\
\hline \multirow{2}{*}{ Civil works } & Construction & \multirow{2}{*}{$\begin{array}{c}\text { Auto CAD, 3D-studio \& auto } \\
\text { desk are used. }\end{array}$} \\
\hline & Architectural & \\
\hline \multirow[b]{2}{*}{$\begin{array}{c}\text { Mechanical } \\
\text { engg. }\end{array}$} & Consultancy & \multirow{2}{*}{$\begin{array}{c}\text { Auto CAD, } \\
\text { CAESARII, CADWOX, } \\
\text { PVELITE, CODE CALC are } \\
\text { used. }\end{array}$} \\
\hline & $\begin{array}{l}\text { Pipe } \\
\text { Networking }\end{array}$ & \\
\hline
\end{tabular}

\section{Construction/architectural companies}

Reports from survey reveal that construction/ architectural companies are the largest user of CAE in the two cities surveyed Lagos and Ibadan. They use CAD in both civil and architectural designs. Packages commonly used are: autoCAD, archi-CAD, 3D-studio, mechanical desktop and autodesk inventor. Archi-CAD is used for architectural/building designs and drawings. While 3Dstudio is used for animation and analysis of stress on beams and effect of weight of roofs on buildings. Response from engineers further shows that autodesk inventor is employed in three-dimensional solid modeling. Materials processing industries

These industries include glass manufacturing, polymers, textiles, consumer products and food industries. Survey report shows that this generality of industries make use of automatic injection molding machines in their manufacturing processes. However in a glass manufacturing company in Ibadan, 3 CNC machines are available. They are CNC cutting machine, CNC polishing machine and CNC curving- furnace. The CNC cutting machine is used for the cutting of glass sheets to required shapes and sizes. Its operation is programmed on an attached computer. $50 \%$ of these industries make use of autoCAD to generate part drawings of worn out machine parts. $20 \%$ have computer numerical control machines used for the mass production 
Fig. 4. Methods of staff development in industries surveyed

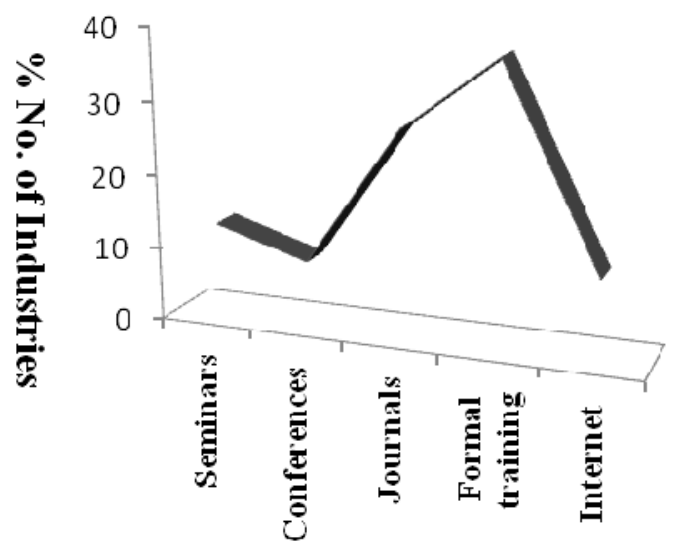

Fig. 5. Percentage of staff with computer experience in

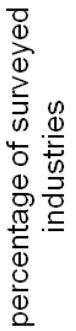

35
30
25
20
15
10
5
0
-5 surveyed companies

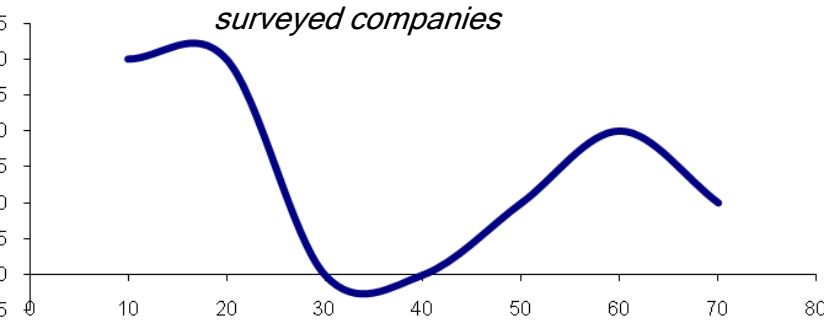

percentage of staff with computer experience

Fig. 6. Computer experience of respondents in industries

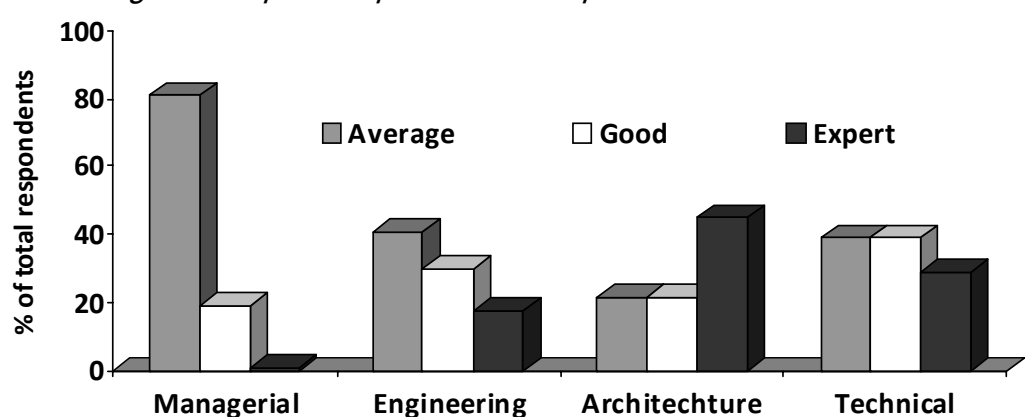

Fig. 7. CAE activities practised in surveyed companies

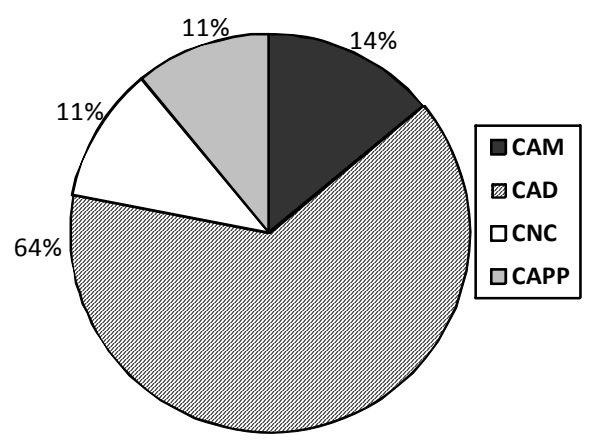

Fig. 8. Decision flow diagram for CMM acquisition based on ROl method.

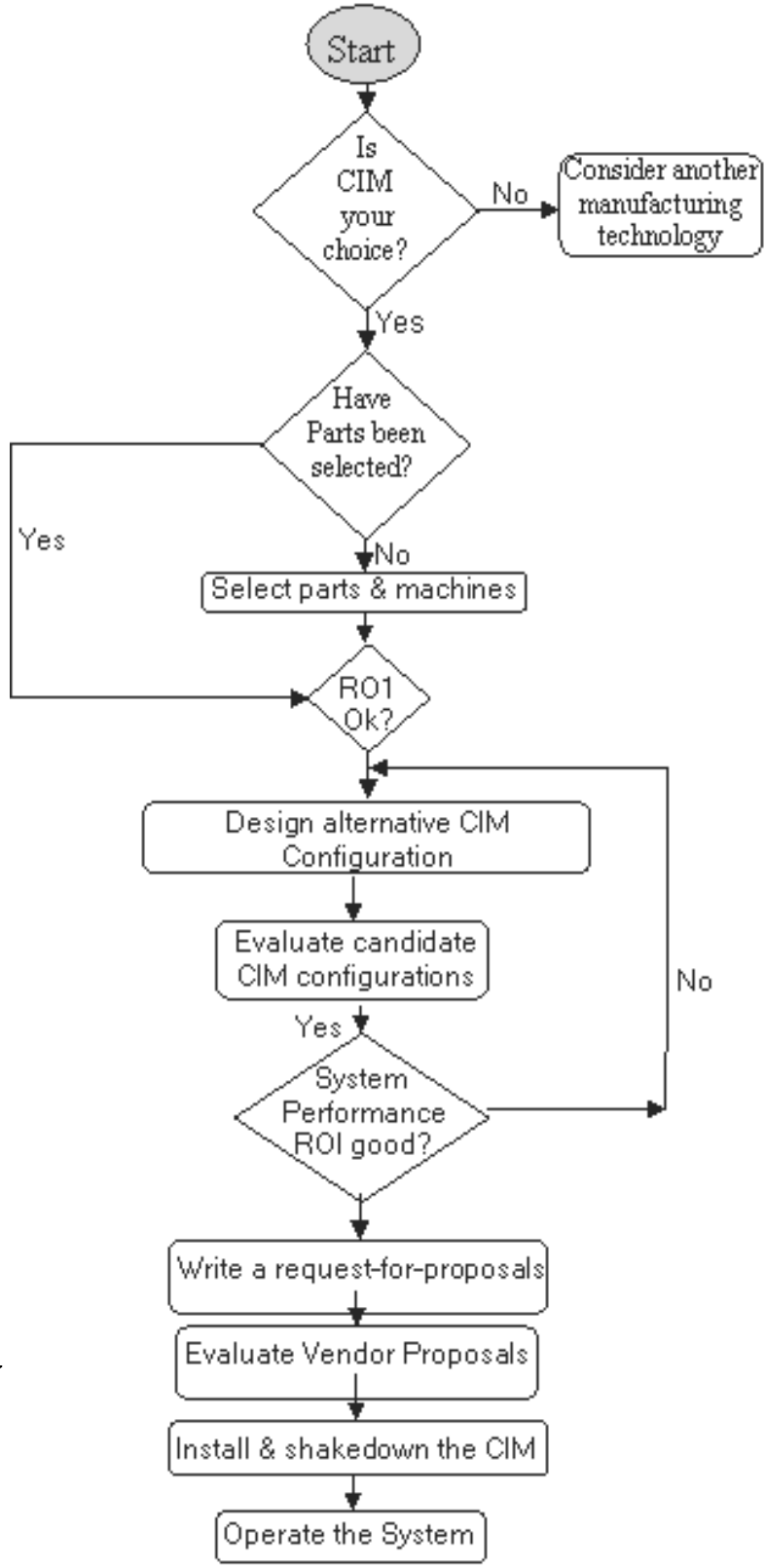

Research article

CIndian Society for Education and Environment (iSee)
"Nigerian industry" http://www.indjst.org
Simolowo et al. Indian J.Sci.Technol. 
of packaging materials such as tins and in sealing products. $60 \%$ use other CAM in monitoring and controlling operations.

\section{Assessment of CAD/CAM application}

The summary of impact of CAD/CAM application in the companies surveyed has shown in Table 2. It reveals that there is a comparative increase in the average savings. More so, from eqn. 1, the return-on-investment (ROI) of CIM systems is greater or better than ROI of conventional methods of manufacturing. Similarly, economic analysis from survey indicates that CIM systems are attractive alternatives for reducing labour costs and are thereby in agreement with engineeringeconomic analysis presented earlier. Fig. 8 shows a decision flow chart for the acquisition of any CAE system such as CIM (computer integrated manufacturing) systems based on the ROI method. This is to ensure the viability of the CAD/CAM applications (Ajayi, 1998).

\section{Suggestions for the improvement of CAE applications Improving personnel training for CAE applications}

The recommendations presented in this section based on findings from this study are suggested to ensure qualitative training, adequate information dissemination and knowledge impartation.

1. Organizing seminars where expertises in CAE from other countries come to deliver lectures and interact with our industrialists and academics for exchange of information.

2. Students willing to delve into CAE should be awarded scholarships in other countries where CAE technology is at its best.

3. Government should also invest strongly on CAE and also lower tariffs on software/hardware importation.

Institutions of higher learning should be mandated to modify their curricula and incorporate CAE application.

Improving CAE applications in the industrial sector

Considering the level of CAE applications in the accessed cities the following suggestions are made for further improvements:

1. More effective means of linking design (CAD) to manufacturing (CAM) should be created. This would enable design information to be forwarded directly to machine tools and thereby create information based systems in manufacturability and cost of design.

2. The design of main CAD software that are more users friendly to the non-technical user should be developed for specific operation in particular industries.

3. CAE centers should be established in learning and research centers and important CAD/CAM equipment installed.

4. More investments should be made on expertise development and equipment acquisition. The problem of cash flow may be resolved by forming links with industries in such a way that the cash is generated in return for training, research and development work with industry.

\section{Conclusion}

It was found out that most of the industries surveyed are not responding adequately or entirely to the challenges of CAD/CAM, even as these challenges intensify. Nevertheless, there is an exception of few enlightened companies who realize the shortcomings of traditional practices of manufacturing and the opportunities that CAE technology and new management approaches will provide.

Computer Aided Manufacturing can provide exponential improvements in efficiency and productivity, but only if the groundwork is laid. The benefits of CAD/CAM will not be fully achieved if the organizational structure and decision-making processes are not harnessed to take advantage of available system. Much improvement on CAE can be achieved by reevaluating the company's operations, especially in design, engineering, and manufacturing to determine the area of comparative advantage or where to start. This varies from company to company with circumstances such as the structure of the industry, particular product line, the market in which the product is sold, and the firm's competitive strategy.

\section{References}

1. Ajayi CA (1998) Property investment valuation and analysis. De Ayo Publ., Ibadan. 2-251.

2. Daniel VH (1989) Computer-integrated manufacturing handbook. Chapman \& Hall Publ. 1-340.

3. Kehinde $\mathrm{OO}$ (2002) A note on computer-aided engineering applications in Nigerian technological and industrial sector. Dept. of mechanical engg., University of Ibadan,Nigeria.

4. Larry DG (1990) Fundamentals of CAD with CADKEY for engineering graphics" Macmillan Publ., NY. 4-178.

5. Okonkwo FC (2002) A note on computer-aided engineering applications in Nigerian technological and industrial sector. Dept. of Mechanical Engg., Univ. of Ibadan, Nigeria.

6. Paul Arthur (1985) CADCAM: Training and education through Proc. CAD ED' 84 Conf. /Kp Springer Publ. 106-2-182.

7. William W L (1988) Fundamentals of numerical control. Delmar Publ., NY. 3-320.
"Nigerian industry" http://www.indjst.org
Simolowo et al. Indian J.Sci.Technol. 